\title{
Carbon balance effects of U.S. biofuel production and use
}

\author{
John M. DeCicco ${ }^{1}$ (D) - Danielle Yuqiao Liu ${ }^{1} \cdot$ Joonghyeok Heo $^{1}$ • \\ Rashmi Krishnan $^{1}$ • Angelika Kurthen ${ }^{1}$ - Louise Wang ${ }^{1}$
}

Received: 5 May 2016 / Accepted: 24 July 2016 / Published online: 25 August 2016

(C) The Author(s) 2016. This article is published with open access at Springerlink.com

\begin{abstract}
The use of liquid biofuels has expanded over the past decade in response to policies such as the U.S. Renewable Fuel Standard (RFS) that promote their use for transportation. One rationale is the belief that biofuels are inherently carbon neutral, meaning that only productionrelated greenhouse gas (GHG) emissions need to be tallied when comparing them to fossil fuels. This assumption is embedded in the lifecycle analysis (LCA) modeling used to justify and administer such policies. LCA studies have often found that crop-based biofuels such as corn ethanol and biodiesel offer at least modest net GHG reductions relative to petroleum fuels. Data over the period of RFS expansion enable empirical assessment of net $\mathrm{CO}_{2}$ emission effects. This analysis evaluates the direct carbon exchanges (both emissions and uptake) between the atmosphere and the U.S. vehicle-fuel system (motor vehicles and the physical supply chain for motor fuels) over 2005-2013. While U.S. biofuel use rose from 0.37 to $1.34 \mathrm{EJ} / \mathrm{yr}$ over this period, additional carbon uptake on cropland was enough to offset only $37 \%$ of the biofuel-related biogenic $\mathrm{CO}_{2}$ emissions. This result falsifies the assumption of a full offset made by LCA and other GHG accounting methods that assume biofuel carbon neutrality. Once estimates from the literature for process emissions and displacement effects including land-use change are considered, the conclusion is that U.S. biofuel use to date is associated with a net increase rather than a net decrease in $\mathrm{CO}_{2}$ emissions.
\end{abstract}

\section{Introduction}

Production and consumption of biofuels, meaning biomass-based liquids such as biodiesel and ethanol, has grown steadily in the United States, from 4.2 billion gallons ( $0.37 \mathrm{EJ} / \mathrm{yr})$ in 2005

Electronic supplementary material The online version of this article (doi:10.1007/s10584-016-1764-4) contains supplementary material, which is available to authorized users.

John M. DeCicco

DeCicco@umich.edu

1 University of Michigan Energy Institute, Ann Arbor, MI 48109, USA 
to 14.6 billion gallons (1.34 EJ/yr) in 2013 (EIA 2015; higher heating value basis). By 2013 biofuels accounted for nearly $6 \%$ of U.S. motor fuel energy consumption. The use of biofuels to displace petroleum has been driven by public policies, including subsidies but most compellingly by regulations, notably the U.S. Renewable Fuel Standard (RFS) and California Low-Carbon Fuel Standard (LCFS). Policy rationales include agribusiness income, energy security, oil depletion and greenhouse gas (GHG) mitigation (Brown and Brown 2012).

The environmental justification rests on the assumption that, as renewable alternatives to fossil fuels, biofuels are inherently carbon neutral because the $\mathrm{CO}_{2}$ released when they are burned is derived from $\mathrm{CO}_{2}$ uptake during feedstock growth (NRC 2011, 195). That convention is premised on globally complete carbon accounting in which biogenic emissions are not counted in energy sectors when carbon stock changes are counted in land-use sectors. This assumption has been used in cap-and-trade programs and carbon taxes as promulgated to date, which address only fossil-derived $\mathrm{CO}_{2}$ emissions. However, errors arise when bioenergy is treated as carbon neutral in national and subnational policies, which do not impose globally coherent accounting that tracks all carbon stock changes (Searchinger et al. 2009).

The carbon neutrality assumption is also embedded in lifecycle analysis (LCA), which traditionally focused only on production-related GHG emissions within a fuel's supply chain. Some LCA models omit biogenic $\mathrm{CO}_{2}$ emissions from the accounting, as in the U.S. Environmental Protection Agency (EPA) analysis of the RFS (EPA 2010a). Others automatically credit biogenic $\mathrm{CO}_{2}$ emissions during their calculations, as in GREET (2011). GREET modeling finds that corn ethanol, the dominant fuel used to comply with the RFS, reduces GHG emissions by 20-50\% compared to petroleum gasoline (Wang et al. 1997; Wang et al. 2012). Such studies have justified biofuel promotion as a both a near- and long-term GHG reduction strategy (Greene 2004; Farrell et al. 2006; CARB 2010) and justify claims that the RFS has reduced GHG emissions to date (BIO 2015).

Once the significance of carbon stock changes, notably those due to indirect land-use change (ILUC), was recognized, traditional (attributional) LCA models were supplemented by economic modeling of market effects. Such consequential LCA methods are used to compute "carbon intensity" (CI) metrics for the RFS and LCFS (EPA 2010a; CARB 2010). However, their results are highly uncertain, undermining confidence in GHG reduction benefits (NRC 2011). These LCA methods now have a system boundary that spans the globe spatially and extends many years into the future temporally. Thus, although it was proposed as an objective way to compare fuels (DeCicco and Lynd 1997; Sperling and Yeh 2009; CARB 2010), LCA has become a form of scenario analysis. However, it is inferior in this regard to integrated assessment modeling (IAM), which uses a biogeochemically and economically coherent analytic framework that LCA lacks (Delucchi 2013; DeCicco 2015). Moreover, as a static framework, it fails to reflect the stock-and-flow dynamics that are fundamental to bioenergy systems (DeCicco 2013; Haberl 2013). Indeed, policy applications of LCA raise serious questions regarding the limitations of the method (Plevin et al. 2014; McManus et al. 2015).

Given such concerns, it is useful to analyze the situation by a method other than LCA. One can empirically examine the direct carbon exchanges associated with the displacement of petroleum fuels by biofuels since the RFS was passed in 2005, a period for which commercialscale data are available. Here, direct exchanges refer to carbon flows, including $\mathrm{CO}_{2}$ uptake and $\mathrm{CO}_{2}$ emissions as well as movements of material carbon, between a vehicle-fuel system and the atmosphere, other parts of the biosphere (notably the food system where biomass used to make biofuels would otherwise be consumed) and the geosphere. Material carbon refers to carbon bound in organic materials (whether recently fixed through photosynthesis or of fossil 
origin) as opposed to $\mathrm{CO}_{2}$. The system to be analyzed includes motor vehicles using fuels regulated by the RFS and the associated fuel supply chains. The latter include farms and oil wells, biorefineries and petroleum refineries, operations that transport feedstocks and distribute fuels, and operations that provide inputs such as fertilizer and purchased energy.

Such a vehicle-fuel system is the subject of attributional LCA as traditionally conducted. It excludes indirect, market-mediated effects outside the system boundary, such as interactions with global commodity markets for energy and for the agricultural products that in turn affect land use. Evaluating market effects requires economic modeling, resulting in the very large and, practically speaking, irreducible uncertainties that bedevil discussions of biofuels and climate. A narrow analysis of direct carbon exchanges cannot provide a complete answer to the question of a biofuel's GHG emissions impact globally. However, it can assess the extent to which $\mathrm{CO}_{2}$ uptake in feedstocks suffices to offset $\mathrm{CO}_{2}$ emissions from fuel combustion, providing a bounding result relevant to the broader question. Although indirect effects can be negative (reducing net emissions) or positive, they are dominated by carbon stock releases due to land-use change (Fargione et al. 2008; Searchinger et al. 2008; Melillo et al. 2009). Therefore, evaluating the offset observable within the vehicle-fuel system provides an upper bound on the net overall offset.

\section{Method}

Evaluating the direct carbon exchanges associated with a given physical system is conceptually straightforward. DeCicco (2012) proposed an Annual Basis Carbon (ABC) accounting method that treats all carbon flows in a spatially and temporally explicit manner. Unlike LCA or other forms of carbon accounting used for climate policy to date, it does not treat biofuels as inherently carbon neutral. Instead, it tallies $\mathrm{CO}_{2}$ emissions on the basis of chemistry in the specific locations where they occur. $\mathrm{ABC}$ accounting reflects the stock-and-flow nature of the carbon cycle, recognizing that changes in the atmospheric stock depend on both inflows and outflows, while LCA focuses only on inflows (GHGs discharged into the atmosphere). It also conforms to a methodology that calls for a consistent system boundary that encompasses both biofuel and fossil fuel pathways (Schlamadinger et al. 1997).

Figure 1 depicts the vehicle-fuel system to be analyzed in terms of material carbon flows, referring to carbon that originates in feedstocks and is utilized as fuel, emitted during processing or exits the system in some other material form. These flows exclude other system inputs and outputs (such as natural gas or other fuels used for process energy and their associated GHG emissions), whose molecular carbon is not part of a feedstock-to-fuel material pathway. Those purely process-related emissions are evaluated separately in a manner similar to that of LCA. The extent to which enduse $\mathrm{CO}_{2}$ is balanced by $\mathrm{CO}_{2}$ uptake is a function of the carbon exchanges shown in Fig. 1. Flows along the top of the diagram are $\mathrm{CO}_{2}$ exchanges between the system and the atmosphere; flows along the bottom are exchanges of material carbon, in either biomass leaving the system or crude oil entering it, with external systems. Cropland is within the system boundary and so $\mathrm{ABC}$ analysis counts carbon uptake regardless of the extent of biofuel use. Although the carbon in biomass output from the system is eventually emitted as $\mathrm{CO}_{2}$ when feed and food products are consumed, these emissions occur outside the vehicle-fuel system and are mediated by complex displacement effects, as described later. 
Fig. 1 Material carbon flows relevant to the substitution of a biofuel for a fossil fuel

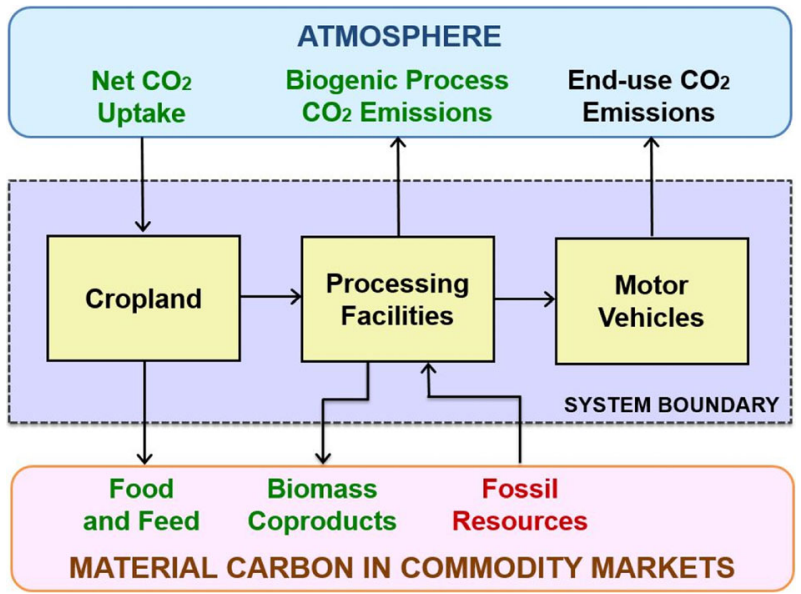

\subsection{Evaluating carbon uptake}

The net amount of carbon taken up by vegetation is net primary production (NPP), which for annual crops ends up in one of several places. A significant portion ends up in the harvest and is removed from the cropland. A portion may accumulate as soil organic carbon (SOC). Some may be lost as organic matter carried by farm runoff or blown from the field by the wind, and some may be oxidized by fire or other non-biological process. A large portion decomposes or is consumed by organisms foraging on the land itself, comprising local heterotrophic respiration $\left(\mathrm{R}_{\mathrm{h}}\right)$. Net ecosystem production (NEP) is the difference between NPP and $\mathrm{R}_{h}$ and it represents the net downward flow of $\mathrm{CO}_{2}$ from the atmosphere in terrestrial ecosystems (Lovett et al. 2006). NEP is not necessarily the same as ongoing carbon accumulation on land; rather, it is the portion of NPP that becomes material carbon available for local sequestration or other disposition.

For a biofuel to provide a net reduction in $\mathrm{CO}_{2}$ emissions, the production of its feedstock must effect a gain in NEP (DeCicco 2013). In other words, it is not sufficient for the feedstock to have merely removed carbon from the atmosphere. Rather, there must be an increase the rate of carbon removal, a test written as:

$$
\mathrm{d}(\mathrm{NEP}) / \mathrm{dt}>0
$$

This condition formalizes the Searchinger (2010) insight about "the need for additional carbon." It can be evaluated over a period of time by calculating:

$$
\Delta \mathrm{NEP}=\mathrm{NEP}_{\mathrm{t} 1}-\mathrm{NEP}_{\mathrm{t} 0}
$$

where $t_{n}$ is a time index (year).

For this analysis, we estimate NEP over 2005-2013 and evaluate $\triangle$ NEP both annually and cumulatively over the period using crop data from the U.S. Department of Agriculture (USDA). From Lovett et al. (2006):

$$
\mathrm{NEP}=\mathrm{NPP}-\mathrm{R}_{\mathrm{h}}=\mathrm{H}+\Delta \mathrm{SOC}+\mathrm{E}_{\mathrm{x}}+\mathrm{O}_{\mathrm{x}}
$$

Here, $\mathrm{H}$ is the carbon harvest, that is, the mass of the carbon embodied in the crops harvested. $\triangle \mathrm{SOC}$ is the change in soil organic carbon on the cropland; $\mathrm{E}_{\mathrm{x}}$ is carbon removed from the 
land by runoff, leaching or wind; and $\mathrm{O}_{\mathrm{x}}$ is carbon oxidized non-biologically, e.g., through fire. As explained in the appendix, for annual cropland $\mathrm{E}_{\mathrm{x}}$ and $\mathrm{O}_{\mathrm{x}}$ are small enough to omit and $\triangle \mathrm{SOC}$ does not differ significantly from zero. We therefore assume $\mathrm{NEP} \approx \mathrm{H}$ and estimate annual changes in net carbon uptake as:

$$
\Delta \mathrm{NEP}_{\mathrm{t}}=\sum_{\mathrm{i}} \mathrm{H}_{\mathrm{i}, \mathrm{t}}-\mathrm{H}_{\mathrm{i}, \mathrm{t}-1}
$$

where

$\mathrm{H}_{\mathrm{i}, \mathrm{t}} \quad$ carbon harvest of crop " $\mathrm{i}$ " at time " $\mathrm{t}$ " (a given year), and

$\mathrm{H}_{\mathrm{i}, \mathrm{t}-1} \quad$ carbon harvest of crop "i" at time " $\mathrm{t}-1$ " (the prior year).

Because harvest data reflect yield gains, increases in carbon uptake due to agricultural intensification are reflected in these estimates of NEP.

\subsection{Other material carbon flows}

Regarding the other flows depicted in Fig. 1, end-use $\mathrm{CO}_{2}$ emissions from motor vehicles are readily computed from fuel consumption data. For biofuels at commercial scale to date, the only significant biogenic process emission is the $\mathrm{CO}_{2}$ during ethanol fermentation. Biofuel coproducts are calculated using biorefining yield factors. The carbon exported to food and feed markets is computed by subtracting the coproduct carbon plus fuel end-use and biogenic process $\mathrm{CO}_{2}$ emissions from the carbon harvest. The fossil carbon input is computed from an average well-to-pump processing factor for crude oil to gasoline and diesel fuel.

\subsection{Other processing emissions and displacement effects}

In addition to the $\mathrm{CO}_{2}$ released through processing or combustion of material carbon, other GHGs are directly released from the system as a result of energy use and other processes within the respective fuel supply chains. These emissions are commonly modeled by attributional LCA and for our purposes there is no need to analyze them independently. We use parameters from EPA (2010b) to make this part of the analysis consistent with EPA's RFS analysis $[\mathrm{A} 1(\mathrm{a})]^{1}$

Changes in flows of material carbon across the system boundary result in changes in the amount of carbon available to the rest of the economy nationally and internationally, causing market-mediated effects of varying sign and magnitude (Hertel et al. 2010). Because they require economic modeling based on limited data, the net impact of such displacement effects is highly uncertain. They include product and co-product substitution, changes in food and feed consumption, agricultural intensification (yield gain) and expansion (land-use change), and petroleum market rebound.

We do not evaluate these displacements but rather cite previously published estimates to put our vehicle-fuel system results in perspective. Overall, displacement effects increase the GHG releases from biofuel use at least for several decades (Melillo et al. 2009; Mullins et al. 2011; Mosnier et al. 2013; Chen et al. 2014; among others). Plevin et al. (2015) show that the carbon releases due to ILUC, which can dominate displacement effects, are most likely to be quite large and very unlikely to be negligible. The net GHG emissions estimate obtained through our

\footnotetext{
${ }^{1}$ See specified appendix section in the supplemental information.
} 
circumscribed $\mathrm{ABC}$ analysis therefore provides a lower bound for the overall (direct plus indirect) GHG emissions impact of existing biofuel systems.

\section{Analysis}

This section has three main parts. The first evaluates the material carbon balance for the vehicle-fuel system to estimate the biogenic carbon offset, comprising the paper's main result. The second and third parts address GHG emissions related to fuel processing and displacement effects, respectively.

\subsection{Material carbon balance}

We calculate vehicle end-use $\mathrm{CO}_{2}$ emissions using fuel carbon content data from EPA (2010b) and fuel consumption data from EIA (2015). Figure 2 shows the resulting estimates in $\mathrm{TgC} / \mathrm{yr}$ (carbon rather than $\mathrm{CO}_{2}$ mass basis; $1 \mathrm{Tg}=10^{12} \mathrm{~g}$ ). The rate at which motor fuel carbon flows into the air declined by $23 \mathrm{TgC} / \mathrm{yr}$, or $5 \%$, from 455 to $432 \mathrm{TgC} / \mathrm{yr}$ over 2005-2013, due to the 2008 recession and vehicle efficiency gains [A1(e)]. However, the biofuel portion of tailpipe $\mathrm{CO}_{2}$ emissions rose from $6.5 \mathrm{TgC} / \mathrm{yr}$ in 2005 to $24.1 \mathrm{TgC} / \mathrm{yr}$ in 2013. In 2013, biofuels accounted for $5.8 \%$ of motor fuel energy end-use and $5.6 \%$ of tailpipe $\mathrm{CO}_{2}$ emissions, up from a $1.4 \%$ share in 2005 .

The other component of biogenic emissions occurs during ethanol fermentation, which yields one mole of $\mathrm{CO}_{2}$ per mole of $\mathrm{C}_{2} \mathrm{H}_{5} \mathrm{OH}$ produced. This release reached $10.2 \mathrm{TgC} / \mathrm{yr}$ in 2013. Combined with biofuel end-use $\mathrm{CO}_{2}$ emissions, the overall increase in motor fuelrelated biogenic emissions was $25 \mathrm{TgC} / \mathrm{yr}$. In policy-oriented carbon accounting to date, these biogenic emissions are treated as carbon neutral. In ABC accounting, how much they are actually "neutralized" (offset) by gains in carbon uptake is a question to be addressed.

\subsubsection{Carbon uptake on cropland}

To estimate $\mathrm{CO}_{2}$ uptake on cropland we used Annual Crop Production (ACP) data from the National Agricultural Statistical Service (NASS; USDA 2015), including planted area, harvested area, average yield and production by crop. For tractability, the analysis was limited to crops that covered at least $95 \%$ of U.S. cropland according to the USDA Cropland Data Layer

Fig. 2 Direct carbon emissions from U.S. motor fuel use, 20002014. Source: derived from EIA (2015)

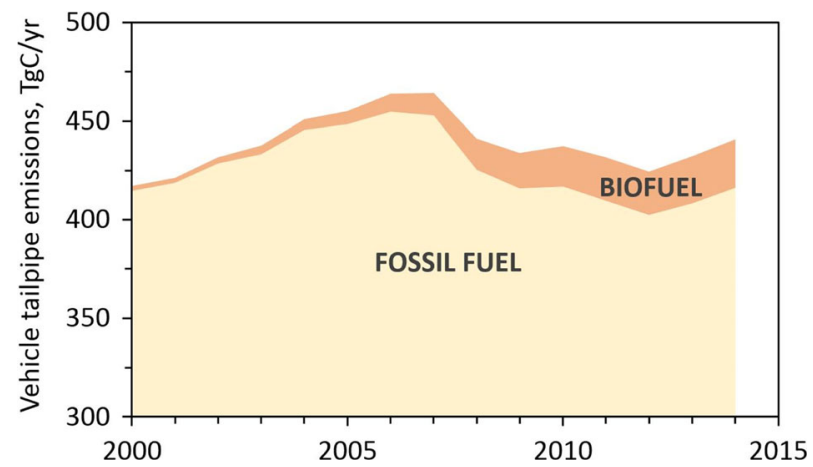


in 2013. We did not attempt to estimate overseas carbon uptake for the small portion of biofuel that was imported, which averaged $5 \%$ of U.S. biofuel consumption over 2005-13 [A1(f)]. Uptake was calculated by multiplying crop production by the fraction of carbon in each crop from composition data adjusted for moisture content [A2]. As shown in Fig. 3, net $\mathrm{CO}_{2}$ uptake rose from 195 to $215 \mathrm{TgC} / \mathrm{yr}$ over 2005-2013. These estimates of NEP reflect the downward flow of carbon from the atmosphere into the part of the biosphere occupied by U.S. cropland.

Carbon uptake is dominated by corn, which has the largest planted area and a higher yield than other crops. The carbon harvest from corn alone rose by $25 \mathrm{TgC} / \mathrm{yr}$ over the analysis period due to a $17 \%$ increase in planted area and a $7 \%$ increase in yield. The corn-soy rotation is the most extensive U.S. farming practice and soybeans are second to corn basis in planted area. However, soybean yields average less than one-third those of corn by volume and only about $25 \%$ those of corn on a carbon basis. With increases of $6 \%$ in planted area and $2 \%$ in yield, soybeans saw a carbon harvest gain of $2 \mathrm{TgC} / \mathrm{yr}$. Nearly all other U.S. field crops saw their planted areas decline over the period. Sorghum was an exception; however, its yield fell and so its harvest did not change significantly. Among other crops, only wheat had a measurable gain in carbon harvest, but by only $0.3 \mathrm{TgC} / \mathrm{yr}$. Collectively, harvests fell for all other major crops, mainly because of smaller planted area, netting out to an aggregate carbon harvest increase of $20 \mathrm{TgC} / \mathrm{yr}$ (about $10 \%$ ) over 2005-2013.

\subsubsection{The biogenic carbon offset}

The observed increases in carbon harvest provide estimates of the increases in NEP over the analysis period. Being smaller than the $25 \mathrm{TgC} / \mathrm{yr}$ increase in biogenic $\mathrm{CO}_{2}$ emissions associated with biofuel use, it is not enough to fully offset those emissions. Because cropland NEP varies annually with economically-driven crop planting decisions and weather-dependent harvest outcomes, the overall offset is estimated by comparing cumulative gains in NEP to cumulative biogenic emissions. These calculations are given in Table 1.

The first section of the table shows year-by-year $\triangle \mathrm{NEP}$ (first differences of the annual carbon harvest values shown in Fig. 3) and the gains in NEP and biogenic emissions relative to

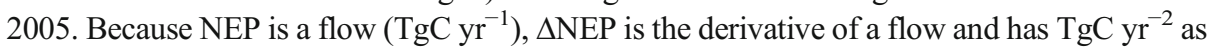
its unit. Being based on harvest data, the annual $\triangle \mathrm{NEP}$ can be positive (a gain in uptake) or negative (e.g., due to a poor growing season). As shown in the table, the aggregate harvest as measured on a carbon basis fell in 2006, meaning that the flow rate of $\mathrm{CO}_{2}$ from the

Fig. 3 Carbon uptake on U.S. cropland, 2005-2013. Source: derived from USDA (2015)

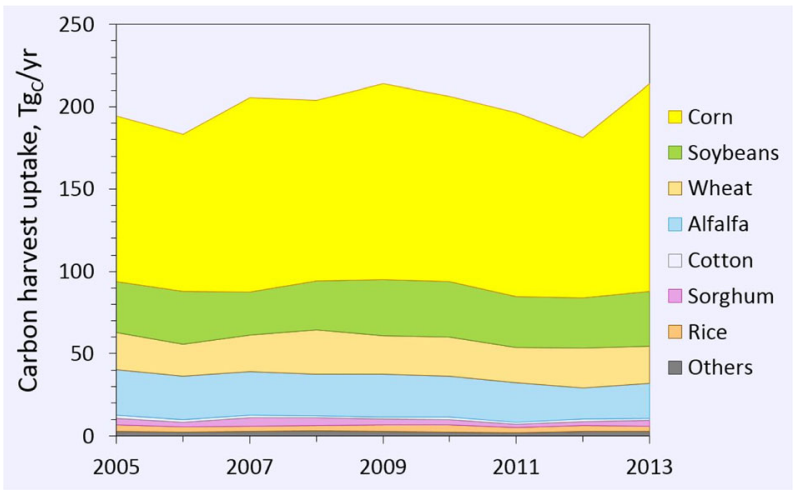


Table 1 Biogenic carbon emissions compared to net gains in carbon uptake

\begin{tabular}{|c|c|c|c|c|c|c|c|c|}
\hline Annual changes & 2006 & 2007 & 2008 & 2009 & 2010 & 2011 & 2012 & 2013 \\
\hline 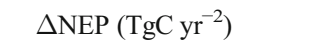 & -11.5 & 22.5 & -2.3 & 10.3 & -7.2 & -10.2 & -13.3 & 31.5 \\
\hline Net NEP gain $\left(\mathrm{TgC}_{\mathrm{yr}}{ }^{-1}\right)$ & -11.5 & 11.0 & 8.7 & 19.0 & 11.8 & 1.6 & -11.7 & 19.8 \\
\hline Biogenic emissions (") & 3.7 & 7.2 & 13.6 & 16.7 & 20.8 & 22.5 & 22.5 & 24.7 \\
\hline \multicolumn{9}{|c|}{ Cumulative effects (running sum, $\mathrm{TgC}$ ) } \\
\hline Additional $\mathrm{C}$ uptake & -11.5 & -0.5 & 8.2 & 27.2 & 39.0 & 40.6 & 28.9 & 48.7 \\
\hline Biogenic emissions & 3.7 & 11.0 & 24.5 & 41.2 & 62.0 & 84.5 & 107.1 & 131.8 \\
\hline Net carbon emissions & 15.2 & 11.5 & 16.3 & 14.0 & 23.0 & 43.9 & 78.2 & 83.1 \\
\hline Percent offset & $-308 \%$ & $-5 \%$ & $33 \%$ & $66 \%$ & $63 \%$ & $48 \%$ & $27 \%$ & $37 \%$ \\
\hline
\end{tabular}

atmosphere to cropland declined, giving a negative value for $\triangle \mathrm{NEP}$ that year. It jumped in 2007 due to a better growing season but also because notably more corn was planted that year. The annual variability of NEP is reflected in the changing sign of $\triangle N E P$ throughout the period.

Integrating $\triangle \mathrm{NEP}$ gives the net change in the rate of carbon uptake since the base year (2005), as shown by the "Net NEP gain" row in Table 1. By 2013, the net gain in NEP was nearly $20 \mathrm{TgC} / \mathrm{yr}$, as can be seen in Fig. 3. To determine cumulative additional $\mathrm{CO}_{2}$ removal from the atmosphere, we integrate again by taking the running sum of the annual gain in NEP. As the integral of a mass flow rate, the resulting values have units of mass $(\mathrm{TgC}$, i.e., millions of metric tons). These results for additional $\mathrm{CO}_{2}$ removal are shown as "Additional $\mathrm{C}$ uptake" in the cumulative effects section of the table and plotted as the green line in Fig. 4.

Similar calculations are performed for the biogenic $\mathrm{CO}_{2}$ emissions. As shown in Table 1, biogenic emissions increase annually because biofuel production rose steadily over the 20052013 period. The cumulative amount of biogenic $\mathrm{CO}_{2}$ that entered the atmosphere is obtained by integrating this flow, yielding the values plotted in black in Fig. 4. By the end of the period, cumulative biogenic emissions reach $132 \mathrm{TgC}$. Cumulative net uptake, which reflects the additional amount of carbon removed from the atmosphere by the cropland beyond what was removed in the base year, sums to $49 \mathrm{TgC}$. The difference between the biogenic carbon emitted and the additional carbon uptake is shown in Fig. 4 as the carbon neutrality "gap," which reaches $83 \mathrm{TgC}$ by 2013 . This value reflects the extent to which biogenic emissions exceeded additional carbon uptake over the analysis period.

Fig. 4 Cumulative carbon emitted by U.S. biofuel use compared to cumulative additional carbon uptake on cropland

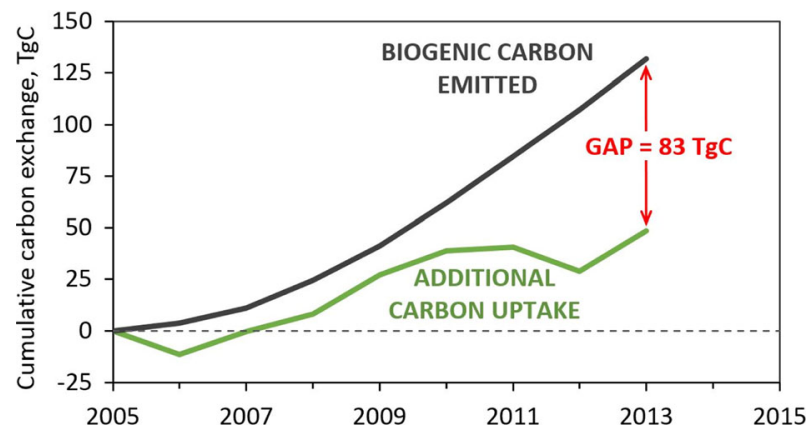


The last line of Table 1 compares cumulative carbon uptake and biogenic emissions in percentage terms, indicating that the additional uptake was enough to offset only $37 \%$ of the increase in biogenic emissions from 2005 to 2013 . This result shows that full carbon neutrality (a $100 \%$ offset) fails for renewable fuel use in the United States over this period. It also shows how the extent of offset depends on the growing season. Because harvests fell in 2006 compared to 2005 (when the RFS was passed), the percent offset is very negative in 2006 and does not become positive until 2008. The cumulative offset reaches a high of $66 \%$ of cumulative biogenic emissions in 2009 before falling again. Although subsequent years of data are needed to make a longer-term estimate, even if biofuel production levels off it seems unlikely that the cumulative offset would reach $100 \%$ anytime soon.

\subsubsection{Vehicle-fuel system carbon balance}

Estimates of the material carbon flows defined in Fig. 1 can be used to construct a carbon mass balance for the vehicle-fuel system, showing inputs by source and outputs according to their disposition [A1(b)]. These balances, which exclude non-material-carbon process emissions, are depicted in Fig. 5.

The carbon harvest is either output from the system as food and feed or refined into biofuel. Some carbon is emitted as $\mathrm{CO}_{2}$ during biorefining and petroleum refining. In biorefining, the primary coproduct is distiller's grain, which is supplied for use as animal feed [A1(c)]. For petroleum refining, the process $\mathrm{CO}_{2}$ emissions estimate assumes a wellto-tank energy efficiency of $81.7 \%$ [A1(d)].

In Fig. 5, the sum of input carbon flows matches the sum of the output flows each year. The total rate of carbon flow through the system fell from $745 \mathrm{TgC} / \mathrm{yr}$ in 2005 to $715 \mathrm{TgC} / \mathrm{yr}$ in 2013, largely due to lower motor fuel demand. Although all of the biogenic carbon emitted comes from NEP (the gross carbon harvest), the gain in NEP over 2005-2013 does not produce enough additional carbon to cover the sum of that which substitutes for fossil carbon in motor fuel plus what gets released during processing. Because the increase in carbon harvest is less than the decrease in fossil carbon input, fuel demand is met at the expense of carbon supplied to the food and feed system. Thus, Fig. 5 reflects how $\mathrm{ABC}$ accounting respects conservation of mass (carbon), in contrast to LCA, which does not ensure conservation of mass because it fails to properly assess carbon uptake.

(a) 2005

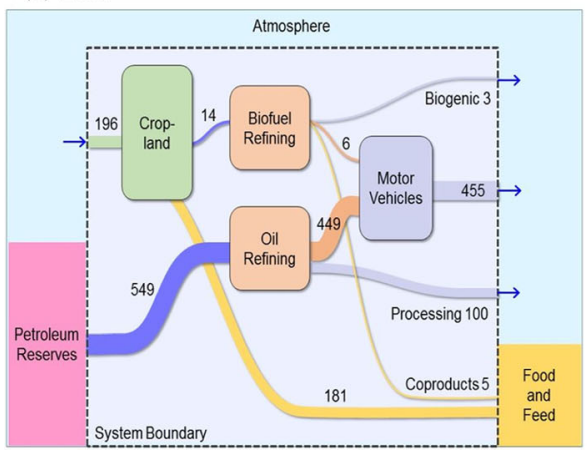

(b) 2013

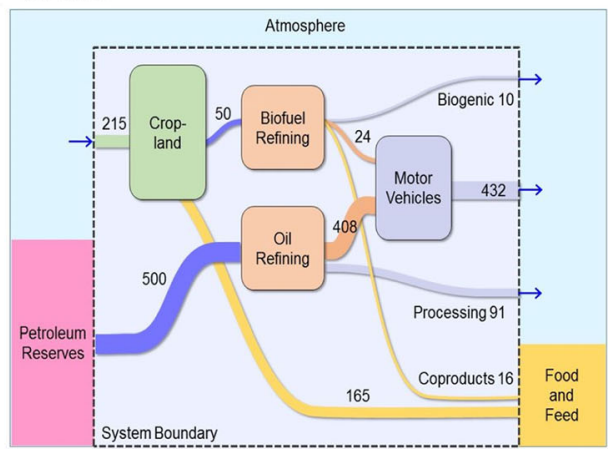

Fig. 5 Material carbon flows through the U.S. vehicle-fuel system (TgC/yr) 


\subsection{Process GHG emissions}

In addition to fuel-related material carbon emissions, GHGs are emitted from feedstock and fuel processing operations. These emissions are the traditional focus of LCA and there is no need to revisit their estimation here. For comparison purposes, we use process emission factors from EPA (2010b).

Adding process emissions to material $\mathrm{CO}_{2}$ emissions yields total net $\mathrm{GHG}$ emissions from the vehicle-fuel system, which dropped by $38 \mathrm{TgC} / \mathrm{yr}$ from 2005 to 2013, i.e., by about $10 \%$ of base year emissions (calculations given in appendix Table A2). This drop is explained by a combination of greater carbon uptake (tallied as negative emissions), lower petroleum input and lower overall fuel demand. GHG emissions from fuel processing increase due to the greater amounts of energy and other inputs needed for producing biofuels compared to petroleum fuels. As seen in Fig. 5, there was a loss of biomass carbon output from the system. Therefore, although the system's net GHG emissions fell, the decrease is only partly from a gain in carbon uptake tied to biofuel use. In gross terms, the $20 \mathrm{TgC} / \mathrm{yr}$ increase in NEP explains just over half of the $38 \mathrm{TgC} / \mathrm{yr} \mathrm{GHG}$ reduction, but that is before considering other important effects such as reduced fuel demand.

\subsection{Displacement effects}

Changes in flows of material carbon across the system boundary change the amount of carbon available to the rest of the economy nationally and internationally. Many effects are indirect, as changes in supply and demand cause changes in price that affect petroleum fuels, grains and other farm products as well as their coproducts, substitutes and other items, affecting GHG emissions the associated markets. These effects include:

- Substitution of agricultural products (including co-products)

- Deprivation of agricultural products (reduced feed and food consumption)

- Intensification of agriculture (increased yield)

- Expansion of agriculture (direct and indirect land-use change)

- Petroleum market rebound (higher demand in non-regulated fuel markets)

Substitution, deprivation and intensification decrease net GHG emissions due to biofuel use while expansion and rebound effects increase net emissions. Because it involves a release of carbon stocks, agricultural expansion can have a very large impact. The other effects involve marginal changes but have magnitudes significant relative to the direct impacts of the vehiclefuel system. Modeling displacement effects is beyond the scope of this study and so we use estimates from the literature, acknowledging their very high uncertainty due to market behavior, differences in modeling methods and data limitations.

Substitution effects are captured by EPA's RFS analysis and so are reflected in the process emissions estimates (Table A2). Evaluating deprivation effects is a new area of research; they may be on the order of one-third of biogenic end-use emissions (Searchinger et al. 2015). Agricultural intensification on U.S. cropland is reflected in the harvest data and so are reflected in our carbon uptake results; we did not attempt to estimate intensification internationally. Petroleum market rebound can amount to as much as one-half of the petroleum fuel displaced by biofuel, raising $\mathrm{CO}_{2}$ emissions in other markets (Chen et al. 2014). The net impact of these interactions is highly uncertain and so it is difficult to ascertain whether their combined effect is either positive or negative.

The displacement effects that clearly increase biofuel-related carbon emissions are direct and indirect land-use change (DLUC and ILUC). For the RFS, EPA projected no significant 
DLUC-induced release of carbon stocks and a small gain in soil carbon by 2022. Nevertheless, the available evidence does not support a gain in soil carbon to date [A4]. For DLUC, Lark et al. (2015) examined the 2008-12 subset of our 2005-13 analysis period and estimated a cumulative release of $36 \mathrm{TgC}$ associated with the biofuel-related expansion of U.S. cropland [A5(a)].

For ILUC, EPA's RFS analysis amortizes carbon stock releases over a 30-year future time horizon. For $\mathrm{ABC}$ analysis, releases are counted in the years when they occur, and so we summed the EPA (2010c) projections of ILUC-induced $\mathrm{CO}_{2}$ releases each year over 20052013, implying a cumulative $433 \mathrm{TgC}$ release over the 8-year period [A5(b)]. Although any such projection is highly uncertain, the DLUC and ILUC releases clearly overwhelm the changes in direct vehicle-fuel systems emissions.

\section{Discussion}

These results demonstrate the value of going back to basics for addressing the $\mathrm{CO}_{2}$ effects of biofuel use. $\mathrm{ABC}$ accounting focuses on the terms for which the best data are available and which can be evaluated with minimal reliance on assumptions. The analysis is therefore narrow in scope and does not attempt to quantify the overall GHG impact of biofuels production and use. ABC accounting does not replace LCA, but it does call LCA results into question, underscoring warnings about the method's ability to mislead (Plevin et al. 2014).

Because $\mathrm{ABC}$ accounting does not generate a lifecycle metric such as a CI value, its results cannot be directly compared to LCA results. Moreover, ABC accounting is sensitive to system dynamics, in contrast to LCA's treatment of a system as static over a defined lifecycle. Nevertheless, the finding of a $37 \%$ offset of biogenic emissions over the period analyzed rather than the $100 \%$ offset assumed in LCA highlights the discrepancy. For example, take a typical attributional LCA result claiming that corn ethanol is $44 \%$ less carbon intensive than petroleum gasoline (Wang et al. 2012). Using a $37 \%$ offset of biogenic emissions instead of a $100 \%$ offset would imply that corn ethanol is $27 \%$ more carbon intensive than gasoline even before considering land-use change $[\mathrm{A} 1(\mathrm{~g})]$. Of course, this $\mathrm{ABC}$ result is for a specific period of time and so makes no claim to offer a general characterization of corn ethanol. The method thereby respects the fact that the seemingly simple question of comparing the carbon intensity of one fuel to another is an ill-posed question empirically.

The differences between $\mathrm{ABC}$ accounting and LCA are more profound than numerical comparisons can reveal. One fundamental distinction is that the $\mathrm{ABC}$ approach treats biofuels as part of a dynamic stock-and-flow system. This differs from LCA, in which biofuel use is modeled as a static system, i.e., one presumed to be in equilibrium with the atmosphere in terms of its material carbon flow, that is compared to a distinct system involving the flow of fossil carbon into the atmosphere. A related difference is ABC accounting's explicit evaluation of additionality by tracking changes in carbon uptake (NEP) when feedstocks are sourced.

Although it does not address leakage, which would require global modeling, $\mathrm{ABC}$ accounting clearly delineates $\mathrm{CO}_{2}$ flows between the vehicle-fuel system and the atmosphere from flows of material carbon with external markets. It thereby respects conservation of mass, which LCA-based fuel comparisons do not. This distinction highlights the weakness of even consequential LCA methods that fail to evaluate additionality but claim to offer correct carbon accounting because they model leakage effects such as ILUC. Finally, the core aspects of ABC accounting - including its estimation of the extent of offset - have a low level of uncertainty 
because the carbon uptake and vehicle emissions estimates reflect the composition of directly measured material flows for feedstocks and fuels.

This paper does not attempt a consequential analysis, which would entail modeling a counterfactual scenario against which actual 2005-2013 carbon exchanges are compared. Such an analysis is left for future work. More broadly, there is a need to develop analytic tools with a resolution and transparency suitable for addressing sectoral measures that target transportation fuels. Liquid fuels can couple strongly to energy and agricultural markets and therefore require dynamic analysis, ideally using commodity data for empirical validation as done here. It would be useful to conduct $\mathrm{ABC}$ evaluations of other programs, such as California's LCFS. The method can also prospectively assess emerging biofuel technologies that process cellulosic feedstocks. Such options may enable greater gains in NEP, e.g., by using crop residues that reduce $\mathrm{R}_{\mathrm{h}}$ or by using feedstocks that raise NPP. Finally, given how different this approach is from the methods commonly used for energy analysis, further work is needed to examine the research and policy implications going forward.

\section{Conclusion}

This retrospective, national-scale evaluation of substituting biofuels for petroleum fuels applied Annual Basis Carbon accounting to take a circumscribed look at the changes in carbon flows directly associated with a vehicle-fuel system. The system was defined to include motor fuel consumption, fuel processing operations and resource inputs, including cropland for biofuel feedstocks. The assumption that biofuels are inherently carbon neutral is a premise of most climate-related fuel policies promulgated to date, including measures such as the LCFS and RFS that evaluate GHG impacts using lifecycle modeling. However, this analysis found that the gains in $\mathrm{CO}_{2}$ uptake by feedstock were enough to offset biofuel-related biogenic $\mathrm{CO}_{2}$ emissions by only $37 \%$ over 20052013, showing that biofuel use fell well short of being carbon neutral even before considering process emissions.

When this estimate of the real-world offset is considered together with values from the literature for displacement effects, the conclusion is that rising U.S. biofuel use has been associated with a net increase rather than a net decrease in $\mathrm{CO}_{2}$ emissions. This finding contrasts with those of LCA studies which indicate that even crop-based biofuels such as corn ethanol and soy biodiesel offer modest net GHG reductions. The global GHG impact of biofuel use remains highly uncertain. Nevertheless, the necessary condition for a biofuel to offer a $\mathrm{CO}_{2}$ mitigation benefit, namely, that the production of its feedstock must increase NEP, can be evaluated empirically. Doing so provides a bounding result that suggests a need for greater caution regarding the role of biofuels in climate mitigation.

Acknowledgments The work reported here was supported by the American Petroleum Institute (API) and the University of Michigan Energy Institute (UMEI). The analysis, results and conclusions presented are those of the authors alone. The conclusions and views expressed do not necessarily, and should not be taken to, reflect those of either API or UMEI.

Open Access This article is distributed under the terms of the Creative Commons Attribution 4.0 International License (http://creativecommons.org/licenses/by/4.0/), which permits unrestricted use, distribution, and reproduction in any medium, provided you give appropriate credit to the original author(s) and the source, provide a link to the Creative Commons license, and indicate if changes were made. 


\section{References}

BIO (2015) The renewable fuel standard: a decade's worth of carbon reductions. Report. Biotechnology Innovation Organization, Washington, DC, http://www.bio.org accessed 24 August 2015

Brown RC, Brown TR (2012) Why are we producing biofuels? Brownia, LLC., Ames

CARB (2010) Final regulation order: low carbon fuel standard. California Air Resources Board, Sacramento, approved January 12. http://www.arb.ca.gov/regact/2009/lcfs09/finalfro.pdf

Chen X, Huang H, Khanna M, Önal H (2014) Alternative transportation fuel standards: welfare effects and climate benefits. J Environ Econ Manag 67:241-257

DeCicco JM (2012) Biofuels and carbon management. Clim Chang 111(3):627-640

DeCicco JM (2013) Biofuel's carbon balance: doubts, certainties and implications. Clim Chang 121(4):801-814

DeCicco JM (2015) The liquid carbon challenge: evolving views on transportation fuels and climate. WIREs Energy Environ 4(1):98-114

DeCicco J, Lynd L (1997) Combining vehicle efficiency and renewable biofuels to reduce light vehicle oil use and $\mathrm{CO}_{2}$ emissions. Chapter 4. In: DeCicco J, Delucchi M (eds) Transportation, energy, and the environment: how far can technology take us? American Council for an Energy-Efficient Economy, Washington, DC

Delucchi MA (2013) Estimating the climate impact of transportation fuels: moving beyond conventional lifecycle analysis toward integrated modeling systems and scenario analysis. Proc Washington Acad Sci Fall:43-66

EIA (2015) Monthly energy review. U.S. Department of Energy, Energy Information Administration, Washington, DC, http://www.eia.gov/totalenergy/data/monthly/index.cfm

EPA (2010a) Regulation of fuels and fuel additives: changes to renewable fuel standard program; final rule. US Environmental Protection Agency, Washington, DC, Federal Register 75(58): 14669ff

EPA (2010b) Renewable fuel standard program (RFS2) final regulatory impact analysis. Report EPA-420-R-10006. https://www.epa.gov/sites/production/files/2015-08/documents/420r10006.pdf

EPA (2010c) Fuel-specific lifecycle greenhouse gas emissions results. Spreadsheets provided as part of RFS docket. www.regulations.gov/\#!documentDetail;D=EPA-HQ-OAR-2005-0161-3173

Fargione J, Hill J, Tilman D et al (2008) Land clearing and the biofuel carbon debt. Science 319:1235-1238

Farrell AE, Plevin RJ, Turner BT et al (2006) Ethanol can contribute to energy and environmental goals. Science 311:506-508

Greene N (2004) Growing energy: how biofuels can help end America's oil dependence. Natural Resources Defense Council, New York

GREET (2011) The greenhouse gases, regulated emissions, and energy use in transportation (GREET) model. Argonne National Laboratory, Center for Transportation Research, Argonne, http:/greet.es.anl.gov/

Haberl H (2013) Net land-atmosphere flows of biogenic carbon related to bioenergy: towards an understanding of systemic feedbacks. GCB Bioenergy 5:351-357

Hertel TW, Golub AA, Jones AD et al (2010) Effects of US maize ethanol on global land use and greenhouse gas emissions: estimating market-mediated responses. Bioscience 60(3):223-231

Lark TJ, Salmon JM, Gibbs HK (2015) Cropland expansion outpaces agricultural and biofuel policies in the United States. Environ Res Lett 10:044003

Lovett GM, Cole JJ, Pace ML (2006) Is net ecosystem production equal to ecosystem carbon accumulation? Ecosystems 9(1):152-155

McManus MC, Taylor CM, Mohr A et al (2015) Challenge clusters facing LCA in environmental decisionmaking: what we can learn from biofuels. Intl J Life Cycle Assess 20:1399-1414

Melillo JM, Reilly JM, Kicklighter DW et al (2009) Indirect emissions from biofuels: how important? Science 326:1397-1399

Mosnier A, Havlík P, Valin H et al (2013) Alternative US biofuel mandates and global GHG emissions: the role of land use change, crop management and yield growth. Energy Policy 57:602-614

Mullins KA, Griffin WM, Matthews HS (2011) Policy implications of uncertainty in modeled lifecycle greenhouse gas emissions of biofuels. Environ Sci Technol 45:132-138

NRC (2011) Renewable fuel standard: potential economic and environmental effects of US biofuel policy. Report of the National Research Council. National Academy Press, Washington, DC

Plevin RJ, Delucchi MA, Creutzig F (2014) Using attributional life cycle assessment to estimate climate-change mitigation benefits misleads policy makers. J Ind Ecol 18(1):73-83

Plevin RJ, Beckman J, Golub AA et al (2015) Carbon accounting and economic model uncertainty of emissions from biofuels-induced land use change. Environ Sci Technol 49(5):2656-2664

Schlamadinger B, Apps M, Bohlin F et al (1997) Towards a standard methodology for greenhouse gas balances of bioenergy systems in comparison with fossil energy systems. Biomass Bioenergy 13(6):359-375 
Searchinger TD (2010) Biofuels and the need for additional carbon. Environ Res Lett 5:024007

Searchinger T, Heimlich R, Houghton RA et al (2008) Use of U.S. croplands for biofuels increases greenhouse gases through emissions from land-use change. Science 319:1238-1240

Searchinger T, Hamburg S, Melillo J et al (2009) Fixing a critical climate accounting error. Science 326:527-528

Searchinger T, Edwards R, Mulligan D et al (2015) Do biofuel policies seek to cut emissions by cutting food? Science 347:1420-1422

Sperling D, Yeh S (2009) Low carbon fuel standards. Issues Sci Technol 25(2):57-66

USDA (2015) Annual crop production data. United States Department of Agriculture, National Agricultural Statistics Service, Washington, DC, Accessed by queries to www.nass.usda.gov/Quick_Stats/

Wang M, Saricks CL, Wu M, Loos D (1997) Fuel-cycle fossil energy use and greenhouse gas emissions of fuel ethanol produced from U.S. Midwest Corn. Argonne National Laboratory, Center for Transportation Research, Argonne

Wang M, Han J, Dunn JB et al (2012) Well-to-wheels energy use and greenhouse gas emissions of ethanol from corn, sugarcane and cellulosic biomass for US use. Environ Res Lett 7:045905 